\title{
BIZANCIO, LA PERSIA SASÁNIDA, LOS BÚLGAROS Y LA DISPUTA ÁVARO-TURCA POR EL CONTROL DE LAS ESTEPAS. 557-603.
}

José Soto CHica Universidad de Granada. España

Centro de Estudios Bizantinos, Neogriegos y Chipriotas.

Resumen: Uno de los episodios menos estudiados de la secular disputa que Bizancio y la Persia sasánida mantuvieron entre sí por el control del antiguo Oriente, es el relativo a las complejas maniobras diplomáticas y militares que ambas potencias emprendieron en la segunda mitad del siglo VI para hacerse con el control y el apoyo de dos nuevos imperios nómadas surgidos en las estepas y montañas de Europa oriental y Asia Central: el imperio ávaro y el imperio de los turcos kok occidentales. En última instancia la rivalidad bizantino-sasánida por el control de las estepas determinó no sólo la historia de ambos imperios, sino también la de Europa oriental y Asia Central.

Palabras clave: Bizancio - Persia sasánida - Estepas - Ávaros. Turcos kok - Eslavos - Búlgaros

\section{BYZANTIUM, SASANIAN PERSIA, BULGARIAN AND AVAR-TURKISH' DISPUTE FOR THE CONTROL OF STEPPES. 557-603.}

Abstract: One of the less studied episodes of the secular dispute between Byzantium and Sassanid Persia held by the control of the ancient East, is relative to the complex maneuvers both diplomatic and military that the two powers launched in second half of the sixth century to gain control and support two new nomadic empires emerged in the Eastern Europe and Central Asia's steppes and mountains: the Avar empire and the rule of Western Turks Kok. Last resort, the rivalry of Byzantium and the Sassanian Persia for control of the steppes, determined not only the History of both empires, but also the Eastern Europe and Central Asia.

Key words: Byzantium - Sassanian Persia - Esteppes - Avars - Turkish Kok - Bulgars.

Recibido:03.04.2014 - Aceptado: 05.05.2014 
José Soтo Chica: Bizancio, la Persia Sasánida, los Búlgaros y la disputa Ávaro-Turca...

Correspondencia: José Soto CHICA.

josesotochica@ugr.es

Doctor en Historia Medieval por la Universidad de Granada Telf.: 640119

040 Universidad de Granada-Centro de Estudios Bizantinos, Neogriegos y

Chipriotas de Granada. Dirección: Gran Vía 9, 2 A, 18001 Granada (España).

Tacia 551 Jordanes y el continuador de Zacarías de Melitene,

Inos dibujan el cuadro general de las estepas pónticas y norcaucásicas en los días inmediatamente anteriores a la llegada de los ávaros a esas mismas regiones. Jordanes ${ }^{1}$ coloca a los búlgaros en las estepas meridionales del Mar Negro que se extendían al Oriente de las riberas del Dniéper. Más allá de ellos, en el Norte de Crimea y al Este del Don, sitúa a otros dos pueblos a los que llama hunos: los alziagiros, a los que ubica al Norte de la ciudad griega de Querson, y a los sabiros, un poderoso pueblo ogur que había llegado a las estepas del Norte del Cáucaso hacia 463. Jordanes cita aún a otro pueblo, el de los hunoguros, los onoguros citados por Prisco y a los que Nicéforo llamaría hunogunduros, un pueblo proto-búlgaro que había llegado a las estepas norcaucásicas ca.460. De este último, nos dice Jordanes que comerciaban con pieles de marta, dato que parece ponerles en relación con la región situada en los límites norteños de las estepas norcaucásicas y en vecindad con los pueblos de los bosques del Sureste de Rusia.

El cuadro dado por Jordanes es muy importante, pues al situar a los búlgaros en el lugar que ocupaban los cutriguros, los identifica por completo con ellos. Esta identificación se hace aún más clara si se tiene en cuenta que Jordanes atribuye a esos mismos búlgaros las desgracias producidas en el Imperio por la incursión que los cutriguros llevaron a cabo en 551.

Esta identificación también la harán otros muchos historiadores, cronistas y geógrafos bizantinos, relacionando el nombre de búlgaros

${ }^{1}$ Sánchez Martín, J. (2001), Jordanes. Origen y gestas de los godos, Madrid, V. 35-38, p. 77-68 [en adelante: Jordanes, Gética]. El nombre de búlgaros aparece por primera vez en 499 en el Cronicón del comes Marcelinus [Comes Marcelinus 499, VII.1], si bien los búlgaros ya llevaban diecisiete años, desde 482, estableciendo relaciones con el Imperio romano. 
o Bulgaria no sólo con los cutriguros, sino también con otro grupo fuertemente emparentado con ellos, los utiguros o utriguros que hacia 551 habitaban en las tierras que se extendían entre el curso bajo del Don y la desembocadura del Kubán, el Cufinas de los autores griegos, los cuales señalaban a ese mismo río como el centro vital y original de la primera Bulgaria ${ }^{2}$.

Cutriguros y utriguros estaban enfrentados entre sí gracias a la habilidad de la diplomacia justinianea, que logró también dotarse de un colchón estratégico frente a los ataques de los búlgaros cutriguros, estableciendo una alianza con los antas ${ }^{3}$.

El continuador de la Historia de Zacarías de Melitene completa el panorama ofrecido por Jordanes, situando en las estepas pónticas y norcaucásicas a los alanos y a otros trece pueblos "que habitan en tiendas" 4 . Esos trece pueblos eran los búlgaros, cutriguros, onoguros, saragur, oghur, ak-khazir, heftalitas, ávaros, daru, dirmar, bagarsik, khulas y abdel.

Esta lista de pueblos, compuesta en 551 pero retocada y completada en 569, de ahí que aparezcan los heftalitas y los ávaros, cuyos restos no llegaron a estas regiones hasta 557-558, es realmente fascinante y digna de ser estudiada con detenimiento.

Lo primero que llama la atención, si se lee con cuidado la lista anterior, es que en este caso el nombre de búlgaros es atribuido a los utriguros, pues el resto de tribus que podían ostentarlo, los cutriguros, onoguros, saraguros y oguros, están identificados con su nombre tribal particular.

Hay que resaltar también la mención de los oguros, propiamente hablando, un pueblo que aparece también mencionado hacia 571 por

${ }^{2}$ Golden, P. (2008), “The peoples of the south Russian steppes”, en Sinor, D. (ed.) Cambridge History of Early Inner Asia., 10, 257-262.

${ }^{3}$ Bonev, C. (1983), "Les Antes et Byzance", Etudes balkaniques, 109-120.

${ }^{4}$ Hamilton, F. (1899), Zachariah of Mitylene. Syriac Chronicle, Londres, 152 [en adelante: Zacarías de Melitene]. 
Menandro el Protector, quien los sitúa al Suroeste del Volga, en lo que hoy sería la estepa calmuca ${ }^{5}$.

Así que hacia 551 las estepas pónticas y norcaucásicas se hallaban en buena medida dominadas por tribus que podríamos englobar dentro del pueblo búlgaro, o más prudentemente, entre los protobúlgaros. De hecho, y ca. 557, en el área póntica y norcaucásica sólo había otros dos pueblos capaces de disputarles ese dominio a los proto-búlgaros: los alanos y los sabiros, y estos últimos estaban además fuertemente emparentados con ellos.

Por otra parte, ambos tenían su atención e intereses fijados en las provincias persas y romanas de allende los pasos del Caúcaso, mientras que los pueblos búlgaros se veían más atraídos por la frontera danubiana del Imperio Romano.

En cualquier caso y hacia 557, los pueblos de las estepas pónticas y norcaucásicas no desempeñaban un papel realmente relevante en el gran juego por el dominio del Oriente en que se veían empeñadas la Romania de Justiniano y la Persia de Cosroes I.

Este papel poco relevante de las estepas en la escena internacional de la segunda mitad del siglo VI, se alteró drásticamente con la súbita aparición de los ávaros y de los turcos ghóz o kok.

${ }^{5}$ Blockley, C. (1985), The History of Menander the Guardsman, Liverpool, frag 10, 124-125 [en adelante: Menandro, Historia]. En nuestra opinión tanto la traducción que Blockley hace de los textos de Menandro sobre las embajadas a los turcos, como y sobre todo sus notas geográficas e históricas, contienen no pocos errores que esperamos haber señalado y aclarado en dos trabajos que hemos dedicado al tema con el auxilio de la doctora Maila García. Al respecto véase: García Amorós, M. y Soto Chica, J. (2014), "Menandro el Protector: de Constantinopla a las Fronteras de China. Traducción y estudio de la primera embajada de una potencia cristiana al Asia Central Oriental", Collectanea Christiana Orientalia 11, (en prensa); Soto Chica J. y García Amorós, M. (2014), "L'ambassade de Zemarque de Cilicie. De Constantinople aux frontières de Chine”, en: Mantas, P. - Burnett, Ch. (eds.), Mapping Knowledge Cross-Pollination in Late Antiquity and the Middle Ages, Córdoba (en prensa). Para la situación general de norcaucasia en estos tiempos consúltese Golden, P. (2008), “The peoples..., 256-257; Koestler, A. (1976), The Thirteenth Tribe, Nueva York, 20-25. 
Todo comenzó en 552 cuando el gran imperio de los juan-juan fue aniquilado por sus vasallos rebeldes del Altai, los turcos kok. No entraremos aquí en la vieja discusión sobre la identificación o no de juan-juan y ávaros. En mi opinión, los ávaros eran en su mayor parte los restos de los juan-juan derrotados en 552 por los turcos y que huyeron hacia Occidente buscando refugio entre sus aliados $y$ parientes, los hunos heftalitas. Luego, hacia 557-558, cuando la alianza turco-persa de 557 ensombreció el panorama heftalita, los ávaros, asentados ahora al Sur y al Este del Mar de Aral, reemprendieron su marcha hacia Occidente arrastrando con ellos a tribus integradas hasta ese momento en el imperio heftalita, entre las cuales debían de hallarse los var y los chuni que luego darían pie a la confusión de Teofilacto Simocata ${ }^{6}$.

La llegada de los ávaros a las estepas situadas al Occidente del río Volga desencadenó un cambio radical en la situación preexistente. Los ávaros, deseosos de lograr seguridad y reforzar su disminuido poder, entraron en contacto y alianza con los alanos del rey Sarosio y a través de éste contactaron con el Imperio Romano y le ofrecieron su alianza a cambio de oro y tierras 7 .

Justiniano, cuyas provincias balcánicas acababan de sufrir en 558559 , un ataque de los cutriguros, al que se había respondido con el

${ }^{6}$ Véase: Soto Chica, J. (2010), Bizantinos, sasánidas y musulmanes. El fin del mundo antiguo y el inicio de la Edad Media en Oriente. 565-642, Universidad de Granada. Tesis Doctoral, Granada. La obra de referencia para los ávaros sigue siendo, pese a los años y a manifiestos errores: Avenarius, A. (1974), Die Awaren in Europa, Bratislava; véase también: Golden, P., “The peoples...”, 205-228 y 284-316; Chavannes, E. (1903), Documents sur les tou-kiue (turcs) occidentaux. París, 220-223 y 230-233; Herrmann, A. (1935), History and Commercial Atlas of China, Harvard, 30-32; Minorski, V. (1937), "Hudud al-Alam The Regions of the World. A Persian Geography. 372 AH-982 AD", E. J. W. Gibb Memorial. New Series XI, Oxford, 448; Musset, L. (1982), Las invasiones. Las oleadas germánicas, Barcelona, 215, n. 20; Grousset, R. (1991), El imperio de las estepas, Madrid, 125, y 214-216; Dobrovits, M., “They called themselves Avar - Considering the pseudo-Avar question in the work of Theophylaktos", Transoxiana, versión electrónica (octubre 2003).

${ }^{7}$ Menandro, Historia, frag 4.8-5.4 pp. 48, 50, y 52, trad pp. 49, 51 y 53; De Gruyter, W., Agathias. The Histories, trad. Ortega Villaro, B., Madrid, 2008; Agatías, Historia, V, 383414; Whitby, M. (1986), The History of Theophylact Simocatta, Oxford, VII.8.1-7 [en adelante: Teofilacto, Historia]. 
tradicional recurso de enzarzar a cutriguros y utriguros en una nueva disputa, contempló el ofrecimiento de los ávaros con interés y como un nuevo instrumento para acabar con el problema búlgaro que, intermitentemente, venía sobresaltando al Imperio desde 493.

Es imposible que la alianza romano-ávara se estableciera antes de 560 , pues aunque los ávaros llegaron a las estepas de norcaucasia en 558, la guerra entre cutriguros y utriguros no comenzó sino en 559 y el ataque ávaro contra éstos se realizó con posterioridad a las batallas sostenidas entre sendos pueblos búlgaros en 559. Así que la gran expansión ávara sólo comenzó en 560, si bien no empezó a afectar a cutriguros y utriguros sino a partir de 561. Menandro señala que los ávaros atacaron primero a los zalos, a los onoguros y a los sabiros, tribus todas ellas situadas al Oriente, al Sureste y al Norte de los utriguros y a las que sometieron por completo. Es evidente también que los oguros y los saraguros citados por Zacarías en 551, debieron de ser anexionados al naciente imperio ávaro en este tiempo, 558-561. Mientras que los alanos figuraban como aliados independientes del nuevo poder, que tras someter, bien por la guerra o la intimidación, a los utriguros, cruzaron el Don hacia 561 y sometieron a los cutriguros.

Que ambos pueblos quedaron firmemente sujetos al nuevo imperio ávaro no puede ser puesto en duda, pues el Jagan Baian, jefe de los ávaros desde 562, exigiría una y otra vez a los romanos el pago de las sumas que, hasta 558-559, cobraban cutriguros y utriguros ${ }^{8}$. Ahora bien ¿cuál era la posición de éstos dentro del nuevo imperio de las estepas pónticas y norcaucásicas? Los informes de Menandro aclaran algo esta cuestión, pues presentan a los cutriguros como vasallos de los ávaros, pero con influencia y capacidad militar propias, aunque al servicio de sus nuevos señores. Veremos así a los cutriguros participar en la renovada expansión ávara hacia Occidente. Primero en el ataque contra los antas, 562; luego en sus primeras incursiones contra la frontera danubiana, 563-565. No obstante el dominio ávaro sobre los cutriguros y demás tribus sometidas en su avance, pero

${ }^{8}$ Menandro, Historia, frag 12.6, 138 y 140, trad. 139 y 141. 
no disueltas por él, no era ni absoluto ni continuo. De hecho sería más apropiado hablar de los ávaros como pueblo dominante en una confederación tribal, que como el pueblo soberano de un imperio.

En cualquier caso cutriguros, utriguros y onoguros, pudieron conservar suidentidad tribal dentro del nuevoimperio o confederación tribal. Peor suerte tuvieron zalos, saraguros y altiazuros, cuyos restos pasaron a formar parte de los ávaros o de los grupos búlgaros más fuertes. Sabiros y oguros, por su parte, también sobrevivieron a los ataques ávaros.

Que los ávaros no dominaban de forma absoluta a los cutriguros, a los onoguros y a los utriguros, lo demuestra el hecho de que, arrastradas algunas de sus bandas hacia Occidente por el avance ávaro hacia el Danubio, pudieron abandonar el campo ávaro y sumarse al del rey lombardo Alboino, para marchar con él a Italia. Pues no pueden ser otros los búlgaros que tanto Menandro como Pablo Diácono, citan como integrantes de la confederación de tribus y pueblos -búlgaros, suevos, sajones, sármatas, hérulos, gépidos, panonios y nóricos- que Alboino y sus lombardos llevaron a Italia en $568^{9}$.

Sin embargo, el dominio exclusivo de los ávaros sobre las tribus búlgaras y demás pueblos de las estepas pónticas y norcaucásicas no duró mucho, pues tras ellos marchaban los turcos kok.

Ávaros y turcos eran viejos enemigos. Así que no es de extrañar que los turcos se lanzaran tras los ávaros en cuanto resolvieron el inesperado problema de la sucesión de su Jagan, Bumin, muerto al poco de lograr su decisiva victoria sobre los juan-juan. El nuevo imperio quedó bajo la soberanía de su hijo mayor, pero otorgando el dominio efectivo sobre su parte más occidental al hermano menor del difunto Jagan Bumin, Istemi o Istami, al que las fuentes griegas conocerían como Silzíbulos y las persas como Sinjibu, corrupción del viejo título de Yabgu.

\footnotetext{
${ }^{9}$ Menandro, Historia, frag 12,5, pp. 136, trad 137; Zanella, A. (2000), Storia dei longobardi, Paolo Diácono. Milán, I, 217-219, II.6, 241 y II.26, 265-267 [en adelante: Pablo Diácono, HL]; Avenarius, A., Die Awaren..., pp. 85 y ss; Bona, I. (1984), "Das erste Auftreten der Bulgaren im Karpatenbecken”, Studia Turco-Hungarica 5, 79-112.
} 
Pues bien, el Yabgu Jagan Istemi, cuyo dominio se extendía en un principio desde las laderas occidentales del Altai, hasta las estepas del río Ili y de las riberas orientales del lago Baljash, manifestó muy pronto su deseo de vengarse de los fugitivos ávaros que se habían refugiado en el imperio de los hunos heftalitas.

Para lograr su propósito, en 557 trabó una alianza con el Shahansha persa Cosroes I, quien se apresuró a poner fin a su guerra con Justiniano para sacar provecho de dicha alianza. Al año siguiente $y$ en un formidable ataque en tenaza, turcos y persas invadieron el imperio heftalita y lo sometieron por completo ${ }^{10}$.

Hacia 563 turcos y persas ya habían concluido la conquista del imperio heftalita y se lo habían dividido poniendo el río Oxus (actual Amu Daria) como frontera entre sus dos Estados.

Los ecos de estas victorias turcas llegaron hasta Constantinopla y sin duda también hasta los ávaros. Éstos habían terminado por enfrentarse a los romanos en el Danubio, pero los ejércitos romanos, conducidos por el general Justino, los habían frenado y obligado a mantener las formas ${ }^{11}$. Mientras, mucho más al Este, los turcos proseguían su imparable avance hacia Occidente dominando a las tribus ogur que habitaban en las estepas y bosques entre el Mar de Aral y las riberas orientales del Mar Caspio y del río Volga. Estas

${ }^{10}$ Mohl, J. (1878), Ferdawsi, Le Livre des Rois par Abou'lkasim Firdousi, vols. V-VII. París, vol. VI, 245-285 [en adelante: Firdusi]; Bosworth, C. (1999), History of al-Tabari vol. V, Nueva York, V, 895-897 [en adelante: al-Tabari]; Teofilacto, Historia, 7. VII. 7. 6-9; Menandro, Historia, frags. 4,2-7; 6,1; 9,3 y 10,1. También son imprescindibles los informes del libro 130 de la gran obra historiográfica china del siglo VII: Pien-I-Tien; vid. Stanislas, J., Documents historiques sur les tou-kioue (turcs), http://classiques.uqac. ca. La reconstrucción en la bibliografía contemporánea más sólida puede hallarse en Grousset, R., El imperio..., 125-126; Yarshater, E. (1983), “The Seleucid, Parthian and Sassanid Periods", The Cambridge History of Iran, Cambridge, vol. 3 (2), 214-216; Hambly, G. (1985), Asia Central. Madrid, , 57-60; Christensen, A. (1944), L'Iran sous les Sassanides, Copenhage, 372-373; Chavannes, E., Documents..., 222-230; Teofilacto, Historia, 188.

${ }^{11}$ Festugière, A. (1975), "Évagre, Historie Ecclésiastique”, Byzantion, 45.2, 187-488, V, 1-3 [en adelante : Evagrio, HE]; Agatías, Historia, IV, 22,7; Menandro, Historia, frag. 5,4, p. 53. 
campañas de Istemi debieron de tener lugar entre 563-568 poniendo de nuevo en contacto a turcos y ávaros.

Estos no habían perdido el tiempo. Tras la muerte de Justiniano habían sabido sacar provecho de la torpeza política de su sucesor, Justino II, quien había propiciado la destrucción del reino gépido y su división entre lombardos y ávaros. División efímera, pues Alboino decidió marchar a Italia en 568 y ceder toda la Gepidia, la Panonia y la Nórica a sus aliados ávaros a cambio de que estos atacaran a los romanos y distrajeran sus fuerzas en el Danubio para imposibilitar que las enviaran como refuerzo a Italia ${ }^{12}$.

Así, en 568 el panorama de las estepas occidentales se caracterizaba por la rápida constitución de dos grandes y nuevos imperios en vías de consolidación y hostiles entre sí: el de los turcos kok occidentales del Yabgu Istemi y el de los ávaros del Jagan Baian.

Curiosamente, hacia esa misma fecha, los dos imperios bárbaros se habían enemistado con sus iniciales aliados persas y romanos. La alianza turco-persa de 557 había terminado por hacerse añicos en 567 y por esas mismas fechas los ávaros, atraídos hacia el Oeste por la alianza romana, habían roto por completo con la Romania.

Pero el enemigo de mi enemigo es mi amigo e Istemi aplicaba a rajatabla este axioma. Por eso en 568 envió una embajada al Augusto Justino II. Una embajada que fue recibida de forma entusiasta y que logró una alianza ofensiva y defensiva contra persas y ávaros, a la sazón enemigos de turcos y romanos. Para terminar de sellar dicha alianza y preparar la futura coordinación de las operaciones contra los persas, un embajador romano, Zemarjos, partió hacia el país de los turcos por la ruta del Cáucaso. El hecho de que pudiera efectuar su viaje por semejante ruta nos indica que la situación en las estepas norcaucásicas era confusa y el dominio ávaro sobre ellas se había resquebrajado seriamente ${ }^{13}$.

12 Soto Chica, J. (2012), Bizantinos y sasánidas: de la lucha por el Oriente a las conquistas árabes. 565-642, Granada.

${ }^{13}$ El relato de la primera embajada turca en: Menandro, Historia, frag 10,1-3, 10,112,114 y 116; trad , 111,113,115 y 117. Para la traducción al español de esta embajada véase: 
Hemos señalado que para 568 el dominio turco debía de haber llegado a las orillas orientales del Volga y del Mar Caspio. Por esa misma fecha los ávaros se concentraban en el Danubio y daban inicio a su fallida ofensiva contra Sirmio. En dicha ofensiva participaron muchos cutriguros, Menandro menciona a 10.000 de ellos devastando Dalmacia e Iliria en 569-570. Por esas mismas fechas y hasta 573, Baian, el Jagan ávaro, reclamaba a los romanos una y otra vez, que le entregaran las sumas que antes recibían cutriguros y utriguros, puesto que él era ahora su señor, y puesto que los romanos no ponían en duda la base de esta reclamación, sino tan sólo su legalidad y oportunidad, podemos concluir que hasta 572-573 los ávaros dominaron a los utriguros $^{14}$. ¿Pero y a las demás tribus norcaucásicas?

Según Menandro, cuando Zemarjos, el embajador enviado por Justino II a la corte de Istemi, el Yabgu Jagan de los turcos kok occidentales, regresaba a Bizancio en el verano de 571, se encontró con que el dominio turco sobre las tribus del Norte del Mar Caspio era ya muy fuerte y que ese dominio se estaba extendiendo más allá del Volga, al punto que los oguros que habitaban al Suroeste de este río y en la futura estepa calmuca eran ya fieles vasallos del Yabgu Jagan Istemi ${ }^{15}$.

El relato de Menandro no tiene desperdicio. Primero nos muestra que la expansión turca ya había llegado a las estepas norcaucásicas en 571. Luego nos pone al corriente de hasta dónde había logrado llegar dicha expansión en 571: no más allá de la estepa calmuca y de las riberas occidentales del Volga. Más allá de dichos territorios el control

García Amorós, M. y Soto Chica, J., "Menandro el Protector...” y el de la embajada de Justino II a los turcos en Menandro, Historia, frag 10,3-5,116, 118, 120, 122, 124 y 126; trad. $117,119,121,123,125$ y 127.

${ }^{14}$ Menandro, Historia, frag 12, 5-6, 136, 138, 140, 142 y 144, trad 137, 139, 141, 143 y 145; Golden, P., “The peoples..., cap. 8, 208; Avenarius, A., Die Awaren..., 87.

${ }^{15}$ En mi opinión, Blockley, el traductor al inglés de los fragmentos de Menandro, equivoca toda la geografía de las embajadas bizantino-turcas. Blockley sigue aquí a Chavannes y espero deshacer los equívocos con la publicación de los dos trabajos antes citados: García Amorós, M., y Soto Chica, J. “Menandro el Protector...”; Soto Chica, J. y García Amorós, M., "L'ambassade de Zemarque de Cilicio..." 
turco aún no se hacía sentir y de los datos arriba mencionados sobre los ávaros, podemos colegir que estos últimos tan sólo controlaban ya a los utriguros y que probablemente habían perdido el dominio sobre sabiros y onoguros y que su alianza con los alanos había quedado en suspenso, de suerte que su dominio al Oriente del Don había quedado circunscrito a las estepas que se asomaban a las costas orientales del Mar de Azov.

Las hipótesis anteriores se ven confirmadas por los datos proporcionados por Menandro, Teofilacto Simocata, al-Tabari y otros autores bizantinos y perso-islámicos. Y así, cuando estalló la guerra de romanos y turcos contra los persas en 572 , los turcos dieron inicio a las operaciones con un doble ataque que golpeó de forma simultánea la frontera Norte de Persia a ambos lados del Sur del Mar Caspio, en Gurgan y en el paso del Derbend ${ }^{16}$.

Ambos ataques fueron rechazados. Pero lo que aquí nos importa es comprender que para que los turcos pudieran lanzar su gran ataque contra las puertas del Derbend en 572 debían de contar ya con una sólida base en el lado Occidental del Volga y que su ataque, de haber triunfado, hubiese traído consigo el sometimiento efectivo y casi inmediato de toda la región norcaucásica. Pero no triunfó. De ahí que alanos y sabiros estuviesen peleando en el bando persa y contra los romanos en 575, algo que no hubiesen hecho si para esa fecha hubieran estado ya bajo el dominio del Yabgu Jagan Istemi, aliado de los romanos desde 568 y feroz enemigo de los persas ${ }^{17}$.

Sin embargo, cuando Valentino, el embajador enviado por Tiberio II a los turcos para renovar la alianza contra los persas, atravesó el norte de la región norcaucásica en la primavera-verano del 576, el panorama político de la región había cambiado considerablemente

${ }^{16}$ Al-Tabari, vol. V, 896, 153. Sobre la correcta cronología de este doble ataque turco contra Persia, véase: Soto Chica, J., Bizancio y los sasánidas..., 49 y 50 y n. 64 de

${ }^{17}$ Menandro, Historia, frag 18,4-5, 162 y 164, trad. 163 y 165; Greatrex, G. (2002), Roman Eastern Frontier and the Persian Wars: Part II, AD 363-630: A narrative sourcebook. Florencia, 153. 
desde que Zemarjos viajara por ella en el verano de 571. En efecto, de las informaciones recogidas por Valentino y anotadas por Menandro se puede saber que los turcos acababan de someter por la fuerza a los onoguros y a los alanos y que los utriguros habían abandonado el campo ávaro para figurar ahora en el de los turcos. De suerte que el imperio turco se extendía ahora hasta el Don por el Oeste y hasta los pasos caucásicos de Darial y Derbend por el Sur.

De hecho del relato de la embajada de Valentino se deduce que toda la región norcaucásica hervía de ejércitos y operaciones militares. Pues a las recientes campañas de los turcos, comandados por uno de los hijos de Istemi, Turxanthos, contra onoguros y alanos, se sumaba la preparación de una inmediata campaña contra los romanos -ahora enemistados con los turcos, por mor de la firma de una paz por separado establecida por Tiberio II con el Jagan ávaro en 574- en la que los utriguros, los búlgaros del continuador de Zacarías de Melitene, desempeñarían un papel fundamental como punta de lanza del avance turco hacia Occidente, cruzando el Don y aspirando a llegar al Danubio para acabar definitivamente con los ávaros. Éstos habían estado demasiado centrados en su lucha con los romanos en el Danubio como para poder acudir en defensa de sus dominios norcaucásicos y de sus viejos aliados, los alanos.

Así que los turcos prosiguieron su avance hacia el Oeste cruzando el río Don y atacando las ciudades de Bósforon (576) y Querson (579), hostigando a los búlgaros cutriguros establecidos entre el Don y el Dniéper y llegando incluso a inquietar la retaguardia ávara en el Danubio. Pues de otra forma no se explica el pánico desatado entre los ávaros que atacaban Tracia en 588 cuando hasta ellos llegó el rumor de que los turcos estaban a punto de desencadenar un ataque contra la región de Sirmio. Era un rumor, pero no puede ponerse en duda que los turcos pretendían expandirse hasta el Danubio, pues en 576, Turxanthos, el jefe turco de la región más occidental, así lo declaró a Valentino y de sus palabras, por bravuconas que fuesen, se deduce a las claras que los exploradores y espías turcos estaban 
ya sondeando las tierras y rutas que se extendían entre el Don y el Bajo Danubio. De hecho es muy posible que entre 579-588 los turcos lograran establecer una suerte de frágil dominio sobre las estepas que se extendían entre el Don y el Dniéper y que con ello controlaran el viejo solar de los búlgaros cutriguros, reuniendo así bajo su dominio la totalidad de las primitivas tierras búlgaras ${ }^{18}$.

De todas formas esta expansión turca más allá del Don no se consolidó y ello por dos razones:

1. Porque desde fines de 585 los turcos occidentales se vieron debilitados por graves problemas internos que degeneraron en una guerra civil en la que el Yabgu Jagan Tardu, el hijo de Istemi, perdió el trono.

2. Porque el interés turco se hallaba fijado en mucha mayor medida en la frontera persa nororiental que en las estepas pónticas y danubianas.

Además, la atracción turca por las provincias nororientales de Persia iba acompañada por el interés ávaro en las provincias balcánicas bizantinas, por lo que ambos imperios bárbaros se hallaban demasiado centrados en sus deseos por obtener contrapartidas de las dos grandes potencias, enfrascadas en su larga guerra de 572-590, como para enzarzarse seriamente entre sí por el control de las estepas del Ponto y de Norcaucasia.

Así que la expansión turca hacia Occidente cesó cuando en 585 Tardu, el Yabgu Jagan de los turcos occidentales, que se había levantado en 583 contra el gran Jagan Nilvar, fue derrotado y destronado.

Este parón en la expansión turca hacia Occidente se confirmó e hizo definitivo cuando Ni-Li, el oscuro sucesor de Tardu en el Jaganato turco occidental, centró toda su atención en saquear las provincias

${ }^{18}$ Menandro, Historia, frag 19,1, 170, 172, 174, 176 y 178, trad 171, 173, 175, 177 у 179;

Golden, P. “The peoples...., 209-210, 260-261 y 303-305; Whitby, M. (1988), The Emperor Maurice and his Historian: Theophylact Simocatta on Persian and Balkan Warfare, Oxford, 112 y 154-155. 
orientales de Persia. Esta última reaccionó en 588 movilizando un gran ejército y poniéndolo bajo el mando del gran general Bahram Chobin quien condujo a sus hombres hacia el Noreste y derrotó por completo a los turcos obligándoles a retroceder más allá del Oxus, saqueando sus posesiones entre este río y el Yaxartes y dando muerte a su Jagan, Ni-Li ${ }^{19}$.

Así que a partir de 588 los turcos no sólo tuvieron que detener su progreso hacia Occidente, sino que perdieron también el control efectivo sobre todas las tierras situadas al Oeste del Volga.

El Jaganato turco occidental cayó en una suerte de anarquía de la que no salió sino en 594 cuando el exiliado Tardu logró retornar al trono e imponer de nuevo su autoridad a las tribus. Para 598 esa autoridad era ya lo suficientemente fuerte como para volver a centrar su mirada en las lejanas fronteras occidentales. Esa y no otra era la intención de Tardu al enviar su embajada de 598 al emperador Mauricio, concentrado en eliminar de una vez por todas el peligro ávaro de su frontera danubiana. Todo lo cual nos lleva a suponer que Tardu buscaba esta vez la alianza y reconocimiento romanos como preludio a la restauración de su dominio efectivo sobre las tribus norcaucásicas, paso previo a una más que posible reanudación de la ofensiva turca contra los ávaros más allá del Don ${ }^{20}$.

Pero no se produjo esa ofensiva y la renovación de los contactos entre turcos y romanos no tuvo ningún efecto positivo en la guerra de Mauricio contra ávaros y eslavos.

Puede que Tardu se hallase demasiado ocupado en el frente persa en donde Cosroes II trataba de someter a Vistahm, su rebelde tío

19 Al-Tabari, V, 991-994, 301-303; Firdusi, VI, 491-502; Teofilacto, Historia, 3, 18,13; Meynard, B. (1962), Les Prairies d’or, 5 vols., París, vol. II, 212, 237; Macler, F. (1995), Histoire D'Heraclius par le évêque Sebeos, París, 11-12; Pourshariati, P. (2011), Decline and Fall of the Sasanian Empire. The sasanian-parthian confederacy and the arab conquest of Iran, Londres, 126-127; Farrokh, K. (2009), Shadows in the desert. Ancient Persia at war, Nueva York, 53-54; Christensen, A., LIran..., 443-444; Golden, P. “The peoples...", 306; Chavannes, A., Documents..., 243-245.

${ }^{20}$ Teofilacto, Historia, VII.7.7-9; VII.8. 8-17 y VII.9-1-2; Golden, P., “The peoples...”, 306307. 
atrincherado desde 594 en el Norte y el Este de Irán y que contaba con el apoyo turco para sostener su dominio sobre el Norte y el Este del Eranshar. Por otra parte, Tardu seguía envuelto en su deseo de lograr un completo dominio sobre la totalidad del Jaganato turco y por ende expuesto a los envites de la política china y por supuesto es más que posible que sus tribus vasallas le dieran más problemas de los que confesaba en su embajada a Mauricio.

En cualquier caso, Tardu no lograría sostenerse mucho en el trono. En el año 600, Vistahm, su aliado persa, perdió la partida y Cosroes II se hizo con el poder absoluto en Persia y ello al tiempo que se frustraban las aspiraciones de Tardu para lograr un dominio absoluto sobre todos los turcos y frente a China. Sin duda los enemigos internos de Tardu aprovecharían estos fracasos para debilitar su posición. Logrando al fin deponerlo por segunda y definitiva vez en $603^{21}$.

Así que los ávaros se vieron libres de un ataque turco y pudieron centrar por completo su atención en las ofensivas romanas contra sus dominios y en restablecer su autoridad en las tierras que se situaban entre el Danubio y el Don. En última instancia y como es bien sabido, la gran ofensiva de Mauricio contra ávaros y eslavos fracasó por mor de la sublevación de Focas quien depondría y asesinaría a Mauricio, dando con este acto la excusa perfecta a Cosroes II para que desencadenara la última gran guerra de la Antigüedad, en la que ávaros, búlgaros y turcos iban a jugar un papel decisivo.

${ }^{21}$ Golden, P., “The peoples..., 307-308; Pourshariati, P., Decline and Fall..., 131-139. 


\section{Referencias Bibliográficas}

AVENARIUS, A. (1974), Die Awaren in Europa. Bratislava.

BLOCKLEY, C. (1985), The History of Menander the Guardsman, Liverpool

BONA, I. (1984), "Das erste Auftreten der Bulgaren im Karpatenbecken", Studia Turco-Hungarica 5, 79-112.

BONEV, C. (1983), "Les Antes et Byzance”, Etudes balkaniques, 109-120. BOSWORTH, C. (1999), History of al-Tabari vol. V, Nueva York.

CHAVANNES, E. (1903), Documents sur les tou-kiue (turcs) occidentaux. París.

CHRISTENSEN, A. (1944), L'Iran sous les Sassanides, Copenhage.

DE GRUYTER, W., Agathias. The Histories, trad. Ortega Villaro, B., Madrid, 2008.

DOBROVITS, M. "They called themselves Avar - Considering the pseudo-Avar question in the work of Theophylaktos", Transoxiana, versión electrónica (octubre 2003).

FARROKH, K. (2009), Shadows in the desert. Ancient Persia at war, Nueva York.

FESTUGIÈRE, A. (1975), “Évagre, Historie Ecclésiastique”, Byzantion, 45.2, 187-488.

GARCÍA AMORÓS, M. Y SOTO CHICA, J., "Menandro el Protector: de Constantinopla a las Fronteras de China. Traducción y estudio de la primera embajada de una potencia cristiana al Asia Central Oriental" Collectanea Christiana Orientalia 11, (en prensa).

GOLDEN, P. (2008), "The peoples of the south Russian steppes", en Sinor, D. (ed.) Cambridge history of Early Inner Asia., 10, 257-262 (edición en línea).

GREATREX, G. (2002), Roman Eastern Frontier and the Persian Wars: Part II, AD 363-630: A narrative sourcebook. Florencia.

GROUSSET, R. (1991), El imperio de las estepas. Madrid. 
HAMBLY, G. (1985), Asia Central. Madrid.

HAMILTON, F. (1899), Zachariah of Mitylene, Syriac Chronicle, Londres.

HERRMANN, A. (1935), History and Commercial Atlas of China, Harvard.

KOESTLER, A. (1976), The Thirteenth Tribe, Nueva York.

MACLER, F. (1995), Histoire D'Heraclius par le évêque Sebeos, París.

MEYNARD, B. (1962), Les Prairies d’or. 5 vols., París.

MINORSKI, V. (1937), "Hudud al-Alam The Regions of the World. A Persian Geography. 372 AH-982 AD”, E. J. W. Gibb Memorial. New Series XI, Oxford.

MOHL, J. (1878), Ferdawsi, Le Livre des Rois par Abou'lkasim Firdousi, vols. V-VII. París.

MUSSET, L. (1982), Las invasiones. Las oleadas germánicas. Barcelona. POURSHARIATI, P. (2011), Decline and Fall of the Sasanian Empire. The sasanian-parthian confederacy and the arab conquest of Iran, Londres.

SÁNCHEZ MARTÍN, J. (2001), Jordanes. Origen y gestas de los godos, Madrid.

SOTO CHICA, J. (2010), Bizantinos, sasánidas y musulmanes. El fin del mundo antiguo y el inicio de la Edad Media en Oriente. 565642, Universidad de Granada. Tesis Doctoral, Granada.

------- (2012), Bizantinos y sasánidas: de la lucha por el Oriente a las conquistas árabes. Granada.

------- y García Amorós, M. (2014), "L'ambassade de Zemarque de Cilicie. De Constantinople aux frontières de Chine" en: Mantas, P. - Burnett, Ch. (eds.), Mapping Knowledge Cross-Pollination in Late Antiquity and the Middle Ages, Córdoba (en prensa).

STANISLAS, J., Documents historiques sur les tou-kioue (turcs), disponible en: http://classiques.uqac.ca

WHITBY, M. (1986), The History of Theophylact Simocatta, Oxford. 
------ (1988), The Emperor Maurice and his Historian: Theophylact Simocatta on Persian and Balkan Warfare. Oxford.

YARSHATER, E. (1983), "The Seleucid, Parthian and Sassanid Periods", The Cambridge History of Iran, Cambridge, vol. 3 (2).

ZANELlA, A. (2000), Storia dei longobardi, Paolo Diácono. Milán. 